\title{
Two Classes of GABAergic Neurons in the Inferior Colliculus
}

\author{
Tetsufumi Ito ( 伊藤哲史 ) , ${ }^{1,2}$ Deborah C. Bishop, ${ }^{2}$ and Douglas L. Oliver ${ }^{2}$ \\ ${ }^{1}$ Department of Anatomy, Faculty of Medical Sciences, University of Fukui, Fukui 910-1193, Japan, and 2Department of Neuroscience, University of \\ Connecticut Health Center, Farmington, Connecticut 06030-3401
}

The inferior colliculus (IC) is unique, having both glutamatergic and GABAergic projections ascending to the thalamus. Although subpopulations of GABAergic neurons in the IC have been proposed, criteria to distinguish them have been elusive and specific types have not been associated with specific neural circuits. Recently, the largest IC neurons were found to be recipients of somatic terminals containing vesicular glutamate transporter 2 (VGLUT2). Here, we show with electron microscopy that VGLUT2-positive (VGLUT2 ${ }^{+}$) axonal terminals make axosomatic synapses on IC neurons. These terminals contain only VGLUT2 even though others in the IC have VGLUT1 or both VGLUT1 and 2. We demonstrate that there are two types of GABAergic neurons: larger neurons with VGLUT2 ${ }^{+}$ axosomatic endings and smaller neurons without such endings. Both types are present in all subdivisions of the IC, but larger GABAergic neurons with VGLUT2 ${ }^{+}$axosomatic terminals are most prevalent in the central nucleus. The GABAergic tectothalamic neurons consist almost entirely of the larger cells surrounded by VGLUT2 ${ }^{+}$axosomatic endings. Thus, two types of GABAergic neurons in the IC are defined by different synaptic organization and neuronal connections. Larger tectothalamic GABAergic neurons are covered with glutamatergic axosomatic synapses that could allow them to fire rapidly and overcome a slow membrane time constant; their axons may be the largest in the brachium of the IC. Thus, large GABAergic neurons could deliver IPSPs to the medial geniculate body before EPSPs from glutamatergic IC neurons firing simultaneously.

\section{Introduction}

The inferior colliculus (IC) integrates virtually all auditory information ascending from the brainstem to the medial geniculate body (MGB), but the output of the IC is unusual since both GABAergic and glutamatergic neurons constitute the MGB projection (Winer et al., 1996; Peruzzi et al., 1997; Bartlett and Smith, 1999; Oliver, 2005). The GABAergic axons in the brachium of the IC (BIC) are large in diameter (Saint Marie et al., 1997b), and when the BIC is stimulated electrically, IPSPs appear in the MGB before the EPSPs (Peruzzi et al., 1997). These data suggest that there are large GABAergic cells in the IC that project to the MGB.

Previous studies have implied the existence of more than one type of GABAergic neuron in the IC. GABAergic cells have been classified according to their size (Roberts and Ribak, 1987; Oliver et al., 1994; Merchán et al., 2005). Dendritic morphology also may distinguish different GABAergic neurons in the cat (Oliver et al., 1994), but such differences are less apparent in the rat (Roberts and Ribak, 1987; Caspary et al., 1990, 1995; Merchán et al., 2005). Despite the implied existence of multiple GABAergic

\footnotetext{
Received July 17, 2009; revised Sept. 30, 2009; accepted 0ct. 4, 2009.

This work was supported by National Institutes of Health Grant DC00189 (D.L.0.) and grants from the University of Connecticut Health Center-Health Center Research Advisory Council (D.L.O.) and The Uehara Memorial Research Scholarship (T.I.). We gratefully acknowledge Dr. Takeshi Kaneko (Kyoto University) for his gift of the VGLUT1, VGLUT2, and VGLUT3 antisera and Drs. Richard Mains, Shigeyuki Kuwada, Srdjan D. Antic, Jennifer Chikar, and Steven J. Potashner for their critical reading of this manuscript. T.I. collected the data for the paper. T.I., D.C.B., and D.L.O. analyzed the data. T.I. and D.L.O. designed the study, made the figures, and wrote the paper. All authors discussed the results and commented on this manuscript.

Correspondence should be addressed to Douglas L. Oliver, Department of Neuroscience, University of Connecticut Health Center, 263 Farmington Avenue, Farmington, CT 06030-3401. E-mail: doliver@neuron.uchc.edu. D01:10.1523/JNEUROSCI.3454-09.2009

Copyright $\odot 2009$ Society for Neuroscience ～0270-6474/09/2913860-10\$15.00/0
}

cell types, little is known about their synaptic organization or axonal targeting.

Recently, it was found that IC neurons differ in the organization of their glutamatergic presynaptic terminals. Vesicular glutamate transporter 1 (VGLUT1) and VGLUT2 identify glutamatergic terminals in the IC (Kaneko et al., 2002; Altschuler et al., 2008). This suggests that glutamate-releasing terminals (Fremeau et al., 2001) arise from different neuronal populations in the lower auditory brainstem (Oliver, 2005). Altschuler et al. (2008) found that the cell bodies and proximal dendrites of large IC neurons are densely covered with VGLUT2 ${ }^{+}$axonal terminals, but smaller IC cells lack this prominent input. Since GABAergic neurons in the IC are larger than non-GABAergic neurons (Oliver et al., 1994; Merchán et al., 2005), we hypothesized that GABAergic cells are the recipients of the dense populations of VGLUT2 ${ }^{+}$axosomatic terminals.

In this report, we show that the VGLUT2 ${ }^{+}$axosomatic synapse is exclusive to the large GABAergic neurons in the IC, a finding that provides a basis for defining two classes of these neurons. Moreover, we show that these larger GABA neurons are the primary source of GABAergic tectothalamic inputs to the MGB. Thus, two types of GABAergic neuron may be distinguished in the IC based on both synaptic organization and axonal projections.

\section{Materials and Methods}

Subjects. Thirteen Long-Evans rats were used. Five rats received an injection of Fluorogold (FG; Fluorochrome). Three rats were used for immunoelectron microscopy. The other animals (five rats) were used for fluorescent immunohistochemistry. All experiments were conducted in accordance with institutional guidelines at the University of Fukui and the University of Connecticut Health Center and in accordance with 
National Institutes of Health guidelines for the care and use of laboratory animals. All efforts were made to minimize the number of animals used and their suffering.

Survival surgery. Rats were anesthetized with ketamine $(28 \mathrm{mg} / \mathrm{kg}$ i.m. and xylazine $(4.3 \mathrm{mg} / \mathrm{kg}$ i.m.) and maintained in an areflexive state with isoflurane mixed with oxygen for the duration of the surgery and recording. Surgery and sound recording were performed in a double-walled sound attenuating chamber (IAC). Acoustic stimuli were generated by a TDT System 2 (Tucker Davis Technologies) under the control of a personal computer, using custom software. All sounds were delivered by Beyer earphones (DT-48) via sealed enclosures. Animals were fixed in a stereotaxic apparatus that used hollow ear bars to deliver sound stimuli. The sound delivery system was calibrated for frequencies from 60 to $40,000 \mathrm{~Hz}$, and calibration was performed at the end of the ear bar with a $1 / 8$ " microphone (Brüel \& Kjaer). A craniotomy opened the right parietal bone. Recordings of sound-evoked activity were used to locate the MGB, and injections into it were made with glass micropipettes $(4-7 \mu \mathrm{m}$ tip, $0.5-5 \mathrm{M} \Omega$ ) filled with $3 \%$ FG diluted in saline. Electrodes were advanced with a microdrive (Burleigh inchworm) mounted on the stereotaxic manipulator. Acoustically driven responses of single or multiple units were amplified with a Dagan 2400 and subsequently amplified again (Princeton Applied Research, model 5113 amplifiers). MGB neurons were identified by responses to white noise bursts or pure tones. In three cases, FG was iontophoretically applied with a $2-5 \mu \mathrm{A}$ current for durations of $2-5$ min with a $50 \%$ duty cycle ( 7 s on/7 s off) (Precision Current Source 51413, Stoelting). In the other cases, pressure injections of $0.5 \mu \mathrm{l} \mathrm{FG}$ were made with a Picospitzer (General Valve).

Pre-embedding immunoelectron microscopy. Rats were deeply anesthetized with chloral hydrate $(400 \mathrm{mg} / \mathrm{kg}$ i.p.) and then perfused transcardially with $4 \%$ paraformaldehyde and $0.05 \%$ glutaraldehyde diluted in $0.1 \mathrm{~m}$ phosphate buffer (PB; pH 7.4). Sections at a thickness of $50 \mu \mathrm{m}$ were cut with a vibratome (Ted Pella) and postfixed for $2 \mathrm{~h}$ with the same fixative. Then, sections were immersed in $50 \% \mathrm{EtOH}$ for $30 \mathrm{~min}$ to enhance antibody penetration (Llewellyn-Smith and Minson, 1992), washed with $\mathrm{PB}$, and incubated for $48 \mathrm{~h}$ at $4^{\circ} \mathrm{C}$ in rabbit anti-VGLUT2 antibody $(0.5 \mu \mathrm{g} / \mathrm{ml})$ (Hioki et al., 2003) diluted with incubation buffer which was composed of $1 \%$ normal goat serum, $0.01 \mathrm{M}$ PBS, pH 7.4, and $0.02 \%$ sodium azide. After the wash, sections were incubated overnight at $4^{\circ} \mathrm{C}$ with goat anti-rabbit IgG (1:200; BA-1000, Vector Laboratories) diluted in the incubation buffer. Finally, tissue was incubated for $2 \mathrm{~h}$ at room temperature with avidin-biotinylated peroxidase complex (PK6200 , Vector) before bound peroxidase was visualized with DAB reaction. Sections were postfixed with $1 \% \mathrm{OsO}_{4}$ in $0.1 \mathrm{M} \mathrm{PB}$ for $45 \mathrm{~min}$, stained en bloc overnight with uranyl acetate, dehydrated with graded $\mathrm{EtOH}$, substituted with propylene oxide, and embedded in Epok812 (Oken shoji). Ultrathin sections were made with an ultramicrotome (EM FCS, Leica Microsystems) and inspected with an electron microscope (H7000, Hitachi).

Immunohistochemistry. Rats were deeply anesthetized with ketamine (56 mg/kg i.m.) and xylazine ( $8.6 \mathrm{mg} / \mathrm{kg}$ i.m.) before being perfused transcardially with $4 \%$ paraformaldehyde in PB. After cryoprotection by $30 \%$ sucrose in PB for 2 days, serial coronal sections were cut at a thickness of $20 \mu \mathrm{m}$ using a freezing microtome. Every 12th section was used for histology. For the analysis of the colocalization of VGLUT1 and VGLUT2, sections were heated with $0.01 \mathrm{M}$ sodium citrate $(\mathrm{pH} 6)$ at $80^{\circ} \mathrm{C}$ for $2 \mathrm{~h}$ to enhance the VGLUT signal (Nakamura et al., 2007). Sections were incubated overnight with one or some combination of the following primary antibodies; rabbit anti-VGLUT2, guinea pig anti-VGLUT2, guinea pig anti-VGLUT1 $(0.5 \mu \mathrm{g} / \mathrm{ml}$, all from Fujiyama et al., 2001), rabbit anti-VGLUT3 (0.5 $\mu \mathrm{g} / \mathrm{ml}$, Hioki et al., 2004), mouse anti-GAD67 (1:1000; MAB5406, Millipore), mouse anti-MAP2 (1:200; MAB3418 Millipore), or rabbit anti-FG (1:2000; AB153, Millipore). All antibodies were diluted in incubation buffer, which was composed of $1 \%$ normal goat serum, PBS, $0.3 \%$ Triton X-100, and $0.02 \%$ sodium azide. The specificity of the VGLUT1, VGLUT2, VGLUT3, and GAD67 antisera was demonstrated previously (Fujiyama et al., 2001; Hioki et al., 2003, 2004; Ito et al., 2007). The specificity of the FG antiserum was confirmed by the absence of staining in tissues which did not contain FG. The specificity of the anti-MAP2 antiserum was demonstrated by Western blotting (ac- cording to the manufacturer's data sheet). It is also noted that this antibody is used extensively (e.g., Varoqui et al., 2002; Blanchart et al., 2006) to visualize dendrites and cell bodies. The next day, sections were washed and incubated with secondary antibodies that were raised from goat and conjugated with AlexaFluor 488, 568, and 647 (Invitrogen). In some cases, Neurotrace488 (Invitrogen) was added to the primary antibody solution. Sections were mounted on coated slides, air dried, rehydrated, and coverslipped with DABCO (1,4-diazabicyclo[2.2.2] octane).

Unless otherwise noted, all images were acquired with a laser scanning confocal microscope (Zeiss 510 META, Carl Zeiss Microimaging). AlexaFluor 488 and Neurotrace 488 were excited by a $488 \mathrm{~nm}$ Ar laser, and the emitted fluorescence was filtered with a $500-530 \mathrm{~nm}$ bandpass filter. AlexaFluor 568 was excited by a $543 \mathrm{~nm}$ He-Ne laser, and the emitted fluorescence was filtered with a $565-615 \mathrm{~nm}$ bandpass filter. AlexaFluor 647 was excited by a $633 \mathrm{~nm} \mathrm{He-Ne}$ laser, and emitted fluorescence was filtered with a $650 \mathrm{~nm}$ low-pass filter. Images of each dye were taken sequentially to avoid bleed-through artifact. Minimal adjustments of the fluorescence intensity levels were made in Photoshop CS3 (Adobe Systems).

Analysis of VGLUT1 and VGLUT2 colocalization in terminals. IC sections immunostained for VGLUT1, VGLUT2, and MAP2 were used for the colocalization analysis. One section from the center of the central nucleus of the IC (ICC) was analyzed in each rat. In each section, the ICC was divided into a $1 \times 8$ or $1 \times 10$ grid with each cell of the grid measuring $142.9 \times 142.9 \mu \mathrm{m}$. The long dimension of the grid was oriented perpendicular to the tonotopic axis of the nucleus. Within each cell of the grid, there was at least one neuron with a dense population of VGLUT2 ${ }^{+}$ axosomatic endings. Within each cell of the grid, we took at least two $z$ stacks of images ( 7 optical slices, $35.7 \times 35.7 \times 2.0 \mu \mathrm{m}, \times 63 / \mathrm{NA} 1.4$ lens, $\times 4$ optical zoom). One $z$ stack contained the neuron with the dense VGLUT2 ${ }^{+}$axosomatic endings, while the second $z$ stack was from a location adjacent to the cell. The $z$-stack images were deconvolved by Huygens software (Scientific Volume Imaging). The fourth optical slice of the deconvolved $z$ stack was used for the analysis using ImagePro Plus software (Media Cybernetics). A threshold for the intensity of the immunostaining was set to define the VGLUT-positive objects, and these objects were further divided by the watershed method, if necessary, to separate terminals. These thresholds for VGLUT divided the terminals into three populations: terminals positive only for VGLUT1, those positive only for VGLUT2, and endings positive for both. Mean intensities of VGLUT1 and VGLUT2 pixels in a single object were plotted. The dense VGLUT2 ${ }^{+}$axosomatic endings in these optical slices were analyzed a second time in images in which only those endings were visible.

Analysis of VGLUT2 axosomatic terminal density on $G A D 67^{+}$neurons. Sections were prepared for VGLUT2 and GAD67 immunofluorescence with a Neurotrace counterstain. To collect GAD $67^{+}$cells in an unbiased way, we used a stereological sampling method. We divided IC sections into a $500 \times 500 \mu \mathrm{m}$ grid, with a $57.1 \times 57.1 \times 20 \mu \mathrm{m}$ box in the center as a sampling frame. If we found nucleoli (stained by Neurotrace) of $\mathrm{GAD} 7^{+}$cells inside the sampling frame, images of those GAD67 ${ }^{+}$cell bodies were captured by a $\times 63$ oil-immersion lens (NA 1.4) with $\times 2.5$ zoom at a $z$ plane which included the nucleoli of the cells. Whole IC sections (six to nine from each animal) separated by $240 \mu \mathrm{m}$ were examined. Additional low-magnification images $(\times 10 / \mathrm{NA} 0.5)$ of the whole IC were taken with an Axiovert microscope, using the ApoTome optical sectioning system (Zeiss). Whole IC images were reconstructed from these low-magnification images. By using these tiled images, we could identify the loci (including the subdivision) of the sampling frames. After sampling the GAD67 ${ }^{+}$cells, we measured the area and perimeter of the cells, counted the number of VGLUT2 ${ }^{+}$axosomatic terminals, and subjectively classified the cells into two categories: cells with dense VGLUT2 ${ }^{+}$axosomatic endings and cells without such endings. Diameter was calculated from the area of the cell bodies. Terminal density was calculated by dividing the number of VGLUT2 axosomatic terminals by the perimeter. To estimate the probability density function between the diameter and the terminal density, we used a kernel density estimation (Parzen, 1962) with an optimal bandwidth (Silverman, 1986). 
Furthermore, we modeled the estimated density with several bivariate Gaussian functions using the least-squares method (MATLAB, Mathworks). The probability density function of the bivariate Gaussian distribution was provided by the following equation:

$$
\begin{array}{r}
y=\frac{1}{2 \pi \sigma_{x} \sigma_{y} \sqrt{1-\rho^{2}}} \exp \left\{-\frac{1}{2\left(1-\rho^{2}\right)}\left(\frac{\left(x-\mu_{x}\right)^{2}}{\sigma_{x}^{2}}+\frac{\left(y-\mu_{y}\right)^{2}}{\sigma_{y}^{2}}\right.\right. \\
\left.\left.-\frac{2 \rho\left(x-\mu_{x}\right)\left(y-\mu_{y}\right)}{\sigma_{x} \sigma_{y}}\right)\right\}
\end{array}
$$

where $\mu_{x}$ and $\mu_{y}$ are the mean of $x$ and $y, s_{x}$ and $\sigma_{y}$ are the SD of $x$ and $y$, and $\rho$ is correlation between $x$ and $y$.

Analysis of the location of GAD67 $7^{+}$neurons in normal material and after retrograde labeling with FG. To plot the locations of GAD67immunofluorescent cells, we took high-magnification $(\times 40$, NA 1.3 , oil-immersion) images with the help of a motor-controlled stage of the entire IC sections, immunostained for GAD67 and VGLUT2 and counterstained with Neurotrace, or immunostained for GAD67, VGLUT2, and FG. These images were then assembled from each section into a single, tiled, montage image (see Fig. 5a) with Illustrator CS3 (Adobe). Tiled images from four evenly spaced $(480 \mu \mathrm{m})$ sections were collected from each animal. The montage IC images were analyzed and plotted with Neurolucida (MBF Bioscience). Three subdivisions of the IC, namely, the ICC and the dorsal and lateral cortex (DC and LC), were identified by Nissl staining (Loftus et al., 2008). Furthermore, GAD67 immunostaining revealed all the IC subdivisions, as well as the modular immunopositive structures in layer 2 of the LC, i.e., GABA modules (Chernock et al., 2004). In this paper, the GABA modules were excluded from the LC and treated as a distinct nucleus. We plotted all the GABAergic neurons and all the cells with dense VGLUT2 ${ }^{+}$axosomatic endings. Neurons with visible nuclei were counted. In one section through the center of the ICC, we measured the size of the cell bodies of GABAergic cells in which nucleoli labeled with Neurotrace could be identified.

\section{Results}

We first describe the localization of VGLUT2 in axosomatic synapses. Next, we demonstrate that the correlation between etween axosomatic and nonaxosomVGLUT2 ${ }^{+}$axosomatic terminals and GABAergic neurons reveals two classes of GABAergic neurons that differ in the prevalence of these terminals. Finally, we provide evidence that the GABAergic neurons with $\mathrm{VGLUT}_{2}{ }^{+}$axosomatic terminals form the major GABAergic component of the tectothalamic projection.

Numerous glutamatergic axosomatic synapses on IC neurons We investigated whether the VGLUT2-containing terminals surrounding large IC neurons (Altschuler et al., 2008) formed axosomatic synapses. IC neurons were examined at the electron microscopic level after pre-embedding immunocytochemistry for VGLUT2. Many VGLUT2 ${ }^{+}$terminals were directly apposed to the cell bodies and primary dendrites of large neurons (Fig. $1 a)$. The neurons frequently had stacked, rough endoplasmic reticulum (Fig. $1 a$, arrowhead) in the perikarya and a highly infolded nucleus (Fig. $1 a$, asterisks). Many VGLUT2 ${ }^{+}$terminals made asymmetrical synaptic contacts on the somata with relatively thin presynaptic but thick postsynaptic densities (Fig. 1b, arrows).

\section{Axosomatic endings contain VGLUT2 but not VGLUT1}

Both VGLUT2 and VGLUT1 proteins were present in the IC (Fig. $2 a-d)$, while no VGLUT3 immunoreactivity was found. Some terminals may contain both VGLUT1 and VGLUT2 (Fig. $2 a-d$, arrowheads). To analyze the colocalization of VGLUT1 and VGLUT2, the intensity of immunofluorescence was measured in

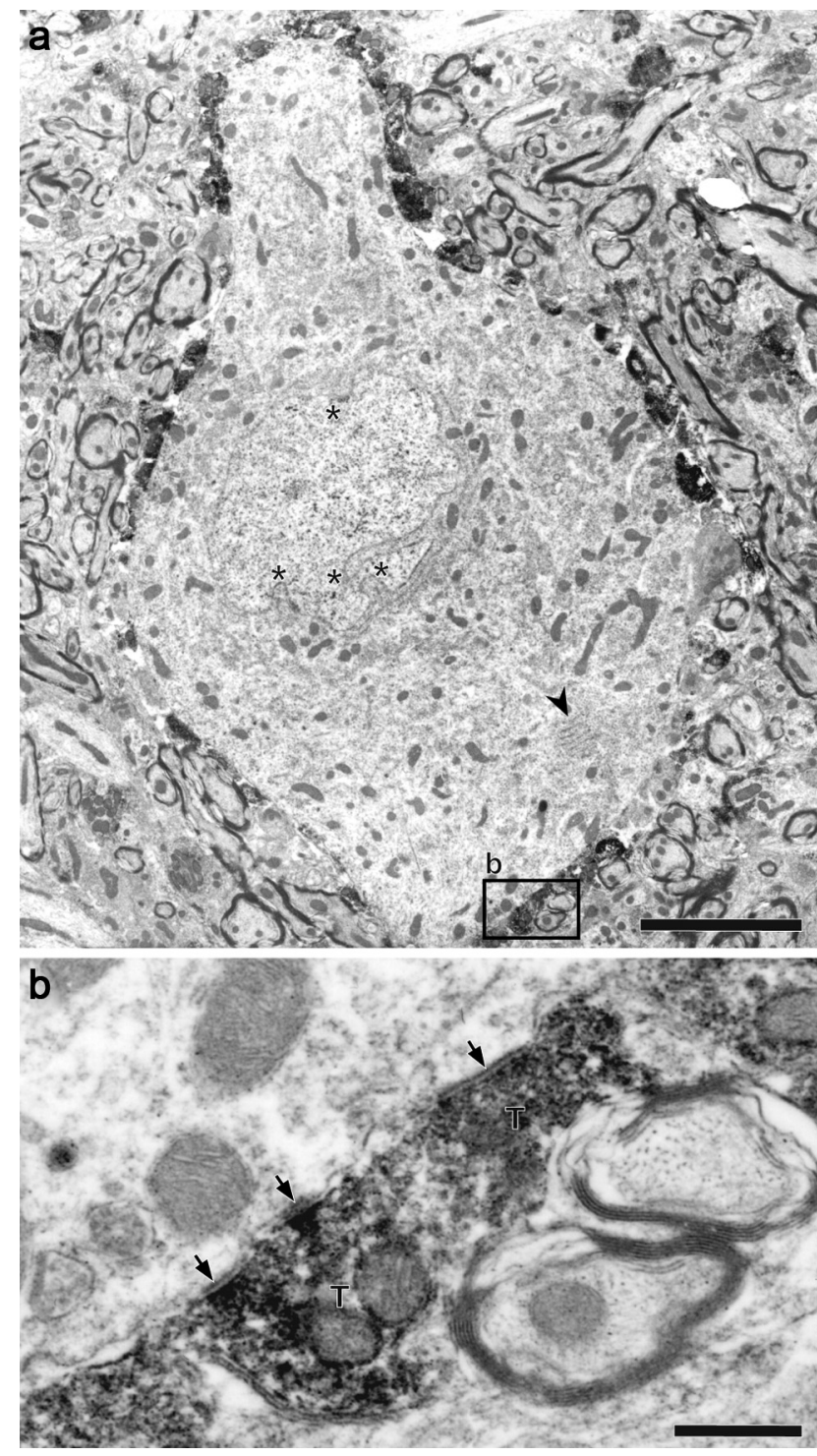

Figure 1. Electron micrograph of large IC neuron with dense VGLUT2 ${ }^{+}$axosomatic endings. $\boldsymbol{a}, \mathrm{VGLUT2}{ }^{+}$terminals contain an electron-dense reaction product and surround the cell body of a large IC neuron which has highly folded (asterisk) nucleus and stacked rough endoplasmic reticulum (arrowhead). The box shows the location of panel b. $\boldsymbol{b}$, Higher-magnification view of synaptic terminals $(T)$ that form asymmetric synapses (arrows). Scale bars: $\boldsymbol{a}, 5 \mu \mathrm{m} ; \boldsymbol{b}, 1 \mu \mathrm{m}$.

13,976 ICC terminals from three rats. In every case, the scatter plot of mean intensity of VGLUT1 and VGLUT2 immunoreactivity showed 3 clusters indicating three patterns of VGLUT localization in synaptic terminals (Fig. 2e): (1) VGLUT1-positive and VGLUT2-negative (VGLUT1 ${ }^{+}$), (2) VGLUT1-negative and VGLUT2-positive $\left(\mathrm{VGLUT}^{+}{ }^{+}\right.$), and (3) positive for both molecules (VGLUT1 and 2). The size of the clusters of VGLUT1 and 2 varied in each of the three cases depending on the methods used to detect VGLUT1.

The most consistent finding was that the terminals that encircled cell bodies and the adjacent proximal dendrites (Fig. 2b) were almost entirely localized to the VGLUT2 ${ }^{+}$category. Indeed, axosomatic endings (1874 terminals, $n=3$ ) were $97.1 \pm 1.8 \%$ $\mathrm{VGLUT}_{2}{ }^{+}$(mean $\pm \mathrm{SD}$ ) and lacked VGLUT1 (Fig. $2 f$ ). In contrast, the nonaxosomatic terminals $(12,102$ terminals) could be $\mathrm{VGLUT}^{+}{ }^{+}$or VGLUT2 ${ }^{+}$. Within the nonaxosomatic terminal population, $\mathrm{VGLUT}^{+}{ }^{+}$terminals represented $34.3 \pm 6.0 \%$, 

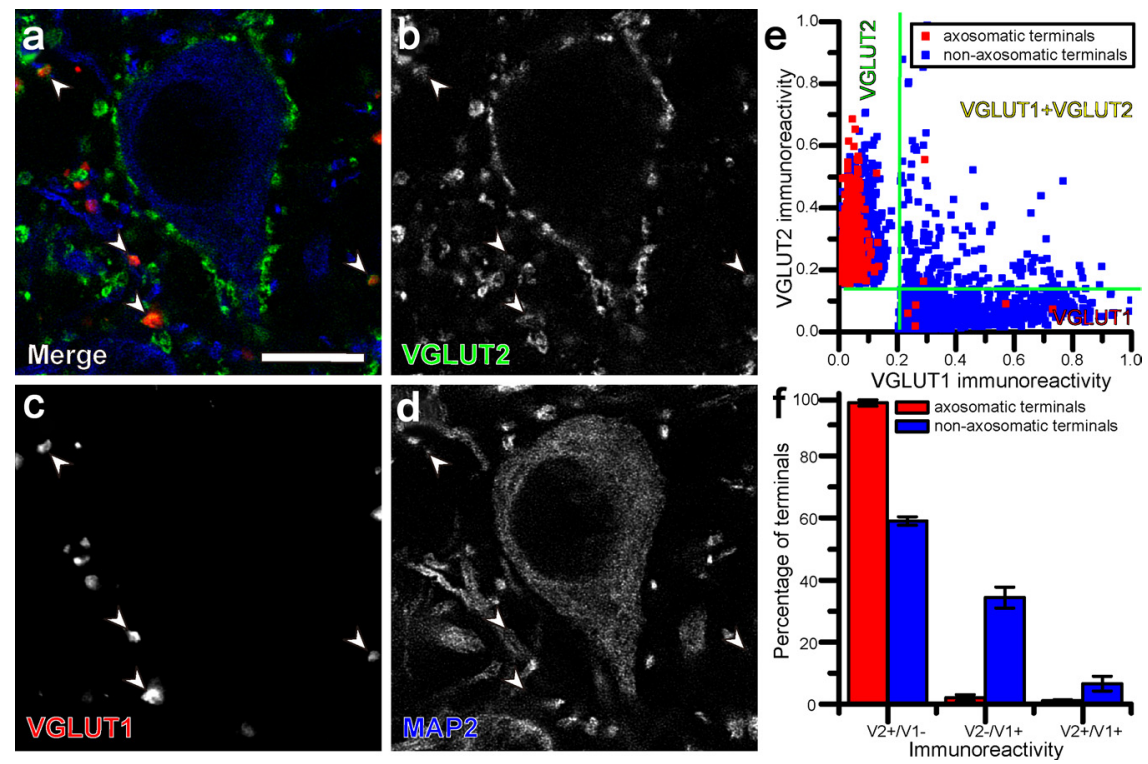

Figure 2. Confocal, deconvoluted micrographs showing three populations of glutamatergic terminals in the IC. $\boldsymbol{a}-\boldsymbol{d}, \mathrm{VGLUT2}{ }^{+}$ terminals (green) contact a neuronal cell body labeled with MAP2 (blue) and its proximal dendrites. VGLUT1 ${ }^{+}$terminals (red) and terminals that are both VGLUT1 ${ }^{+}$and VGLUT2 ${ }^{+}$(arrowheads) are not associated with somata. $\boldsymbol{e}$, Scatter plot of ICC terminals showing mean fluorescence of VGLUT1 and VGLUT2 immunoreactivities. Blue dots indicate terminals which were not apposed to cell bodies or primary dendrites, while red dots indicate terminals encircling cell bodies and primary dendrites. Terminals from one animal are illustrated. $\boldsymbol{f}$, Percentage of terminals immunopositive for only VGLUT2, only VGLUT1, or both. Blue bars indicate proportions of terminals which were not apposed to cell bodies or primary dendrites, while red bars indicate proportions of terminals encircling cell bodies and primary dendrites. Scale bar, $10 \mu \mathrm{m}$.

VGLUT $2{ }^{+}$terminals constituted $59.1 \pm 2.4 \%$ and VGLUT1 and 2 terminals made up $6.6 \pm 4.1 \%$ (Fig. $2 f$ ). A $\chi^{2}$ analysis of the distributions of terminals shown in Figure $2 f$ revealed a significant difference between axosomatic and nonaxosomatic terminals $\left(p<2.2 \times 10^{-16}\right)$. Thus, VGLUT2 can be considered a specific marker for the glutamatergic axosomatic endings on large IC neurons.

\section{Only large GABAergic neurons receive VGLUT2 ${ }^{+}$ axosomatic inputs}

Since GABAergic neurons are larger than non-GABAergic, presumably glutamatergic neurons (Oliver et al., 1994; Merchán et al., 2005), we hypothesized that it is the GABAergic neurons that receive the VGLUT2 ${ }^{+}$axosomatic inputs. Since our GAD67 antibody is a reliable somatic marker of GABAergic neurons (Ito et al., 2007), we examined VGLUT2 axosomatic terminals on GAD67-positive $\left(\mathrm{GAD}^{+} 7^{+}\right)$cells in the IC. Only GABAergic neurons (Fig. $3 a-h$, white arrows) were the postsynaptic recipients of the VGLUT2 ${ }^{+}$axosomatic endings in all subdivisions of the IC (Fig. 3a,d,g, arrows). GABA-negative neurons lacked this input (Fig. $3 c, f, g$, black arrowheads). However, not all of the GABAergic neurons received this special input. Small GAD67 ${ }^{+}$ cells lacked the VGLUT2 ${ }^{+}$axosomatic terminals (Fig. $3 b, e, h$, white arrowheads). Thus, two types of GABAergic neurons are suggested based on differences in the density of VGLUT2 ${ }^{+}$axosomatic endings.

Using stereological methods, we sampled $279 \mathrm{GAD} 67^{+}$cells from four rats, and measured the perimeter and diameter of $\mathrm{GAD} 7^{+}$cell bodies and the density of VGLUT2 ${ }^{+}$axosomatic terminals. The relationship of diameter and terminal density for each GAD $67^{+}$cell is shown in the scatter plots of Figure 4, $a$ to $c$, and Figure $\mathrm{S} 1 a$, available at www.jneurosci.org as supplemental material. In the ICC (Fig. 4a), a bimodal distribution was ob- served when the sample was analyzed with a kernel density analysis (Fig. 4, pseudocolor and contour lines). Larger GABAergic neurons had a higher density of VGLUT2 ${ }^{+}$axosomatic terminals, and smaller GABAergic neurons had a lower density of axosomatic terminals. A cluster of smaller cells was evident in the DC (Fig. 4b), in the LC (Fig. 4c), and in the samples from all subdivisions combined (Fig. S1 $a$, available at www.jneurosci.org as supplemental material).

The kernel density estimate was fitted with bivariate Gaussian distributions to divide the GABAergic cells into two groups. Two-dimensional fits were possible for two populations of GABAergic neurons in the ICC (Fig. 4d), DC (Fig. S1c, available at www.jneurosci.org as supplemental material), and entire IC sample (Fig. S1b, available at www.jneurosci.org as supplemental material). Interestingly, for the larger GABAergic neurons, there is a positive correlation $(\rho=0.49)$ between diameter and axosomatic terminal density (Fig. $4 d$, red contours). This unexpected trend suggests that the axosomatic density actually increases with the size of the larger GABAergic neuron. In contrast, there is no correlation $(\rho=0)$ between the somatic diameter and axosomatic density for the smaller GABAergic cells (Fig. 4d, blue contours). A similar tendency also was found in the DC (Fig. S1c, available at www. jneurosci.org as supplemental material) and entire IC (Fig. S1b, available at www.jneurosci.org as supplemental material).

We compared the two populations of GABAergic IC neurons defined by the Gaussian fit with our subjective classifications of the neurons made at the time of data collection. Points at which the two Gaussian distributions for the ICC have the same probability density were aligned on a slope $y=-0.0071 x+0.41$ (Fig. $4 d)$. This line provides an objective criterion to separate GAD67 ${ }^{+}$ cells into two populations, neurons with and without VGLUT2 ${ }^{+}$ axosomatic terminals, and this criterion fits very well with the classification of neuron type made subjectively. For example, in the ICC sample (92 cells), the subjective classification of GAD $67^{+}$ICC cells is correct $91 \%$ of the time (Fig. $4 e$, Table 1). When the ICC criterion was applied to the whole IC sample, 279 GAD $67^{+}$IC cells, $85 \%$ of the neurons were correctly identified (Fig. 4f, Table 2).

By using the objective criterion in Figure $4 f$, we can provide a guideline to identify the GABAergic neurons based on somatic size alone. Ninety-five percent (154/162) of the GABAergic cells with VGLUT2 ${ }^{+}$axosomatic endings have diameters larger than $10.7 \mu \mathrm{m}$, and $95 \%(111 / 117)$ of the GABAergic cells without $\mathrm{VGLUT}^{+}{ }^{+}$axosomatic endings have diameters smaller than 16.5 $\mu \mathrm{m}$. Thus, large cells (defined as diameter $>16.5 \mu \mathrm{m}$ ) (Fig. S1 $d-g$, available at www.jneurosci.org as supplemental material) always have VGLUT2 ${ }^{+}$axosomatic endings, small cells (defined as diameter $<10.7 \mu \mathrm{m}$ ) (Fig. $S 1 d-g$ ) all lack the axosomatic endings, and medium-sized cells (defined as 10.7-16.5 $\mu \mathrm{m}$ ) (Fig. $S 1 d-g$ ) are a mixture of the two cell types. The perimeter measurements follow the same trend (Fig. $4 g-j$ ) since neurons with perimeters $>60 \mu \mathrm{m}$ all have VGLUT2 ${ }^{+}$axosomatic endings, neurons with perimeters $<30 \mu \mathrm{m}$ always lack the axosomatic 

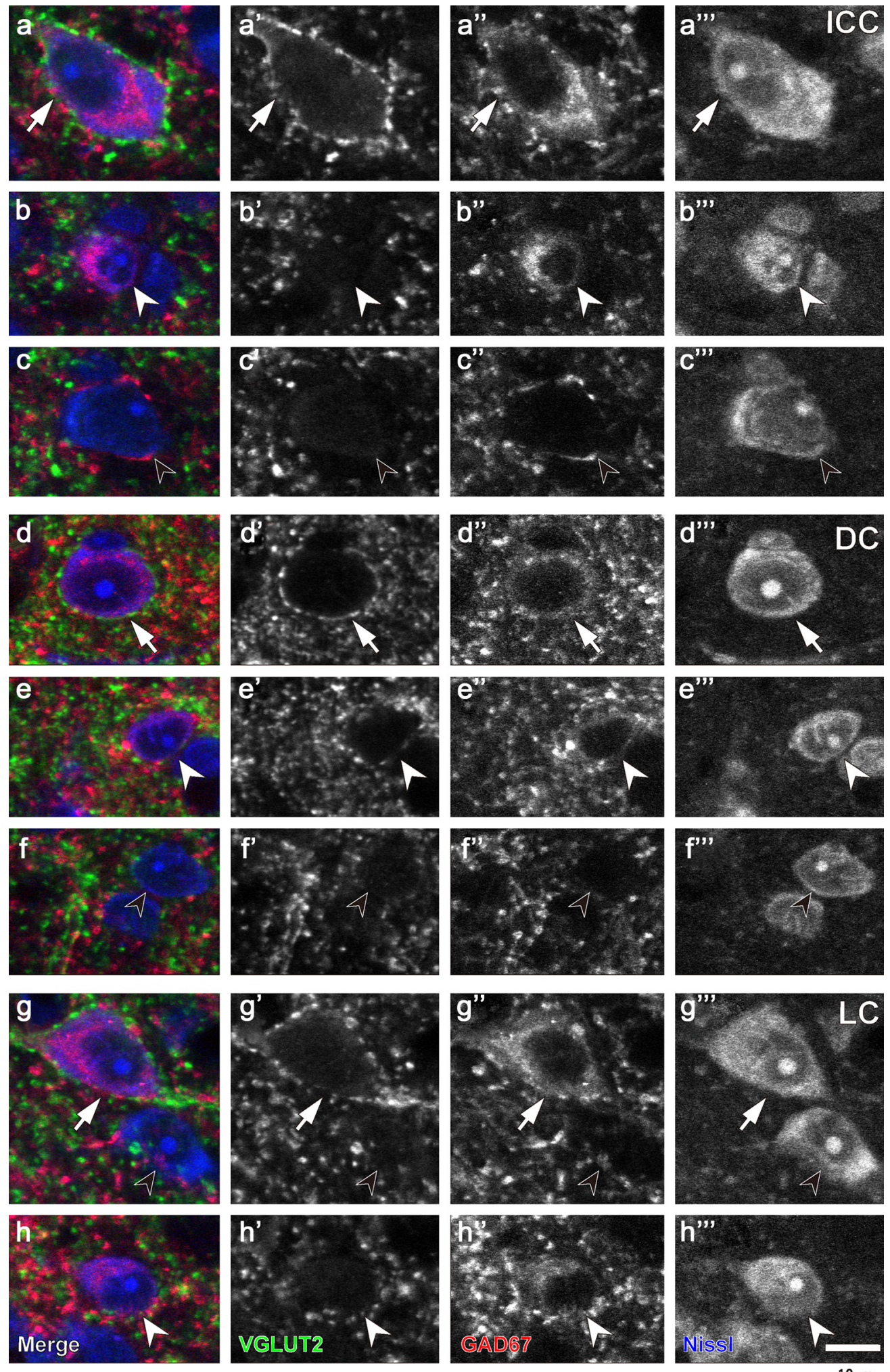

Figure 3. Confocal images that show two types of neurons immunopositive for GAD67 (red). $\boldsymbol{a}, \boldsymbol{d}, \boldsymbol{g}$, Immunopositive cells with dense VGLUT2 ${ }^{+}$axosomatic endings (green) are indicated with arrows. $\boldsymbol{b}, \boldsymbol{e}, \boldsymbol{h}, \mathrm{GAD}^{+}{ }^{+}$cells without VGLUT2 ${ }^{+}$terminals (white arrowheads). $\boldsymbol{c}, \boldsymbol{f}, \boldsymbol{g}$, GAD67-negative cells (black arrowheads) also lack VGLUT2 ${ }^{+}$axosomatic endings. These three types were seen in all IC subdivisions ( $\boldsymbol{a}-\boldsymbol{c}$, ICC; $\boldsymbol{d}-\boldsymbol{f}, \mathrm{DC} ; \boldsymbol{g}$ and $\boldsymbol{h}, \mathrm{LC})$. Scale bar: (in $\left.\boldsymbol{h}^{\prime \prime \prime}\right) \boldsymbol{a}-\boldsymbol{h}^{\prime \prime \prime}, 10 \mu \mathrm{m}$.

endings, and medium-sized cells (perimeter 30-60 $\mu \mathrm{m}$ ) are a mixture of two cell types.

Thus, the results strongly suggest that there are two classes of GABAergic cells, namely, large GABAergic cells with
VGLUT2 $^{+}$axosomatic endings and small GABAergic cells without these endings. Our subjective classification of these cell types separates the two classes very well with error rates of $\sim 7 \%$. 

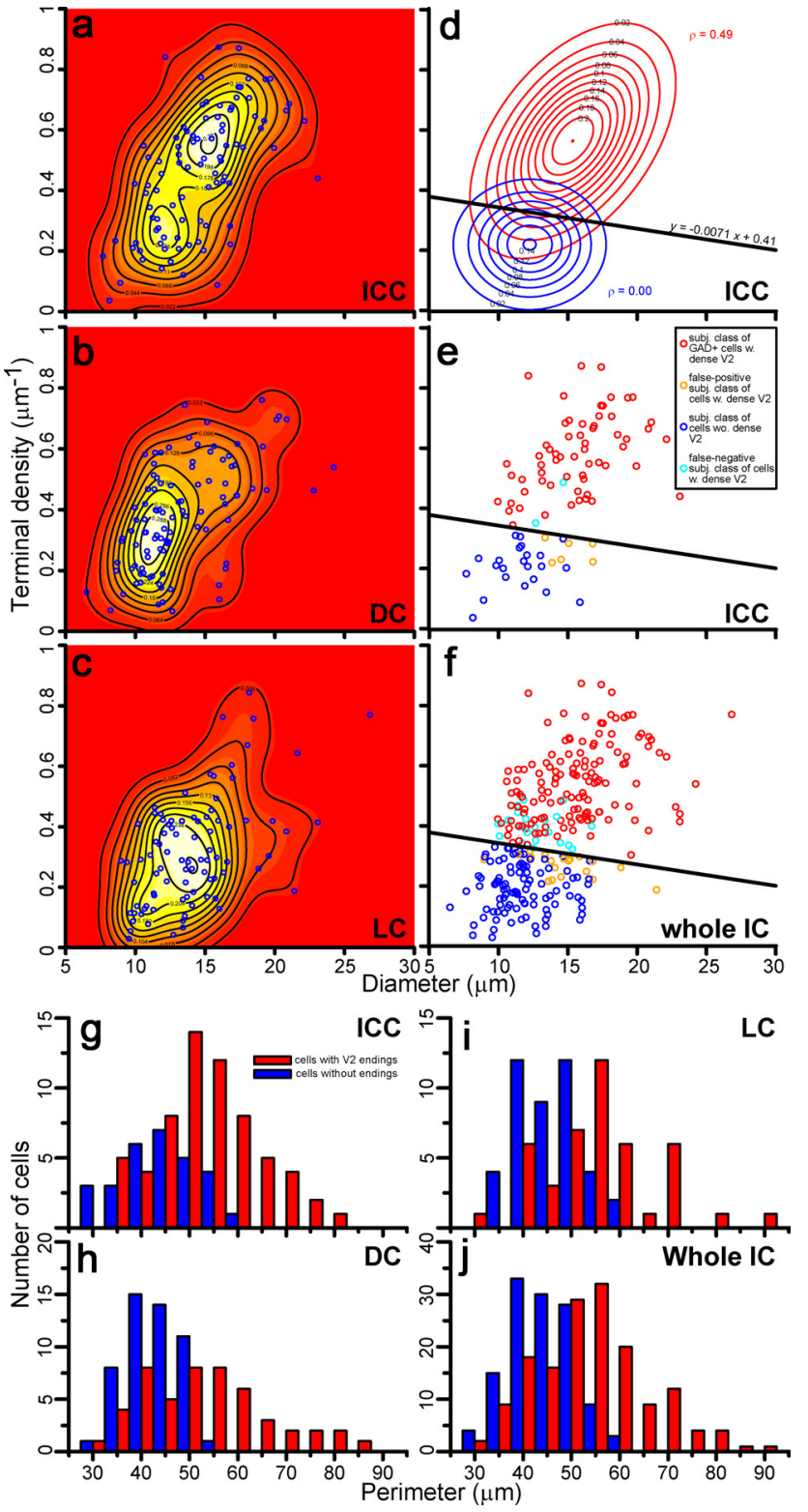

Figure 4. Analysis of $\mathrm{GAD} 67{ }^{+} \mathrm{IC}$ cells based on cell diameter and density of VGLUT2 ${ }^{+}$ axosomatic endings and comparison to subjective classification. $\boldsymbol{a}-\boldsymbol{c}$, Scatter plots of $\mathrm{GAD} 67^{+}$cells (blue circles) in subdivisions of the IC and kernel density estimates of populations. Kernel density estimates are visualized by both color depth (white and red indicate high and low probability density, respectively) and contour plots. $\boldsymbol{d}$, Best fit of bivariate Gaussian distribution to the kernel density estimate from the ICC with two bivariate normal distributions calculated by the least-squares method. The distribution with lower terminal density (blue contours) shows no covariance ( $\rho=0$ ) between diameter and density, while the distribution with higher terminal density (red contours) shows covariance between these parameters $(\rho=0.49)$. Points at which both distributions have the same probability density aligned with a slope $y=-0.0071 x+0.41$. $e$, Scatter plot of the ICC GAD67 ${ }^{+}$cells (circles, 92 cells) is divided by slope $(y)$ into two populations. Neurons were classified subjectively, as VGLUT2-axosomatic positive (red, 61 cells) or VGLUT2-axosomatic negative (dark blue, 23 cells). A few cells were miscategorized and represent false-positive (cyan, 2 cells) and false-negative (orange, 6 cells) choices. See also Table 1. $\boldsymbol{f}$, Scatter plot of all ${\mathrm{GAD} 67^{+}}^{+}$cells in all IC subdivisions classified by our subjective analysis and separated by slope ( $y$ ) used in $\boldsymbol{d}$ and $\boldsymbol{e}$. VGLUT2-axosomatic positive ( 140 cells; red circles) and VGLUT2-axosomatic negative ( 98 cells; blue circles). Errors were 21 false-positive and 20 false-negative cells. See also Table $2 . \boldsymbol{g}-\boldsymbol{j}$, Histograms of perimeter show the distribution of GAD67 ${ }^{+}$cells with or without VGLUT2 ${ }^{+}$axosomatic endings (red and blue bars, respectively) classified objectively in the ICC $(\boldsymbol{g}), \mathrm{DC}(\boldsymbol{h}), \mathrm{LC}(\boldsymbol{i})$, and entire IC $(j)$. In all cases, these two cell types make two distinct but overlapping populations of $\mathrm{GAD} 67^{+}$neurons.
Table 1. Accuracy of classification of GAD67 ${ }^{+}$neurons in ICC

\begin{tabular}{lcc}
\hline Classification & Number of neurons & Percentage \\
\hline w/ VGLUT2 ${ }^{+}$classified correctly & 61 cells & $66 \%$ \\
w/VGLUT2 $^{+}$classified incorrectly & 2 cells & $2.2 \%$ \\
w/o VGLUT2 $^{+}$classified correctly & 23 cells & $25 \%$ \\
w/o VGLUT2 $^{+}$classified incorrectly & 6 cells & $6.5 \%$ \\
\hline
\end{tabular}

w/, with; w/o, without.

Table 2. Accuracy of classification of GAD67 ${ }^{+}$neurons in entire IC

\begin{tabular}{|c|c|c|}
\hline Classification & Number of neurons & Percentage \\
\hline w/VGLUT2 ${ }^{+}$classified correctly & 140 cells & $50 \%$ \\
\hline w/ VGLUT2 ${ }^{+}$classified incorrectly & 21 cells & $7.5 \%$ \\
\hline w/o VGLUT22 ${ }^{+}$classified correctly & 98 cells & $35 \%$ \\
\hline w/o VGLUT2 $2^{+}$classified incorrectly & 20 cells & $7.2 \%$ \\
\hline
\end{tabular}

w/, with; w/o, without.

Distribution and sizes of two classes of GABAergic neurons in the IC

To determine the distribution of VGLUT2 ${ }^{+}$axosomatic endings on GAD $67^{+}$neurons among the IC subdivisions, we investigated all $\mathrm{GAD}^{+} 7^{+}$neurons (3974 cells) and all neurons with VGLUT2 ${ }^{+}$axosomatic endings in four serial sections of the complete IC from three rats. A typical section assembled from 78 confocal images is shown at low magnification in Figure $5 a$. At higher magnification (data not shown), the terminals on the somata appear as in Figure 3 (see also Zoomify images available at http://doliver.uchc.edu/Whole-IC/). The neurons were classified as "VGLUT2 ${ }^{+}$axosomatic" or "without VGLUT2 ${ }^{+}$axosomatic" using the subjective criteria above. VGLUT2 ${ }^{+}$axosomatic terminals encircled 1664 of 3991 cells. Of these, $98.9 \pm 0.34 \%$ were presynaptic to $\mathrm{GAD} 7^{+}$neurons. This confirms the nearly exclusive association of VGLUT2 ${ }^{+}$axosomatic endings with GABAergic neurons shown above.

Neurons with VGLUT2 ${ }^{+}$axosomatic endings were found in all subdivisions of the IC (Fig. 5b). Over the entire IC, $41.5 \pm$ $2.85 \%$ (mean $\pm \mathrm{SD}$ ) of GABAergic neurons were encircled by $\mathrm{VGLUT}_{2}{ }^{+}$axosomatic endings. However, the ratio of GABAergic neurons with VGLUT2 ${ }^{+}$axosomatic endings was significantly higher in the ICC with $\sim 50 \%$ of the neurons receiving this input (Fig. 5b,c, Table S1, available at www.jneurosci.org as supplemental material). Fewer neurons with VGLUT2 ${ }^{+}$axosomatic endings were present in the DC and LC (Fig. $5 b, c$, Table S1). The fewest were observed in the GABA modules in layer 2 of the LC (Chernock et al., 2004) (Fig. 5b,c, Table S1).

We measured the diameter of $\mathrm{GAD} 67^{+}$cells at the focal plane of the nucleolus ( $\mathrm{N}=3,635$ cells). In this sample, there were also two populations of GABAergic neurons based on size. Neurons with VGLUT2 ${ }^{+}$axosomatic endings (Fig. 3, white arrows) were always significantly larger than ones without the terminals (Fig. 3, white arrowheads) in all subdivisions of the IC (Fig. 5b,d, Table $\mathrm{S} 2$, available at www.jneurosci.org as supplemental material) ( $p=0.009$; two-way ANOVA). The larger GABAergic neurons were similar in size in each subdivision but those in the LC were the largest. Smaller GABAergic neurons without axosomatic input were also similar in size in each subdivision.

\section{GABAergic cells with VGLUT2 ${ }^{+}$axosomatic endings project} to the thalamus.

Since IC projections to the MGB produce short latency inhibitory potentials (Peruzzi et al., 1997), and the diameter of GABAergic axons in the BIC is larger than non-GABAergic axons (Saint Marie et al., 1997b), we asked whether the large GABAergic neu- 
rons with VGLUT2 ${ }^{+}$axosomatic endings contribute axons to the tectothalamic projection. We injected $\mathrm{FG}$, a retrograde tracer, into the MGB $(\mathrm{N}=5)$ and examined IC sections immunostained for FG, GAD67, and VGLUT2. A substantial number of neurons showed positive immunoreactivity for both GAD67 and FG (1404 cells from five rats), although, as expected, the majority of FG-positive cells were GAD67-negative (Fig. $6 a-d$, arrowheads).

GAD $67^{+}$neurons with VGLUT2 ${ }^{+}$ axosomatic terminals tended to project to the MGB more often than GAD67 ${ }^{+}$cells without these endings in all subdivisions. In the ICC, the majority $(81.8 \pm 12.4 \%$; mean $\pm \mathrm{SD})$ of the $\mathrm{GAD} 67^{+}$projection neurons were encircled by VGLUT2 ${ }^{+}$ axosomatic terminals (Fig. $6 a, d$, arrows). The percentage in the DC and LC was slightly lower $(68.3 \pm 7.6 \%$ and $75.1 \pm$ $13.3 \%$, respectively), but not significantly different (Tukey's multiple comparison). In the GABA modules, VGLUT2 ${ }^{+}$axosomatic endings contacted $40.3 \pm 18.4 \%$ of the GABAergic projection neurons, significantly fewer than in the ICC, DC, and LC (Tukey's multiple comparison, $p=$ $0.016,0.028$, and 0.034 , respectively). Since the incidence of GABAergic cells with VGLUT2 $^{+}$axosomatic endings is different in each subdivision (Fig. $5 c$ ), the number of these cells contributing axons to the tectothalamic projections is variable. To compensate for this variability, we calculated a preference ratio for the tectothalamic projection and divided the percentage of FG-positive-GAD67 ${ }^{+}$cells with VGLUT2 axosomatic endings (data above) by the percentage of GABAergic cells with VGLUT2 ${ }^{+}$endings for each subdivision (data from Fig. $5 c$ ). In the ICC, only $50 \%$ of the GABAergic neurons have VGLUT2 ${ }^{+}$axosomatic endings, but $82 \%$ of the GABAergic tectothalamic neurons had VGLUT2 ${ }^{+}$contacts, a preference ratio of 1.56. Likewise, the preference ratio in the DC is 1.87 , in the LC it is 1.97 , and in the GABA module it is 2.13. Thus, these data show that the GABAergic neuron with VGLUT2 ${ }^{+}$axosomatic terminals is the predominant GABAergic cell type in the projection from the IC to the MGB.

\section{Discussion}

The present data show that there are two types of GABAergic neurons in the IC with different patterns of synaptic inputs and axonal projections. Large GABAergic cells (diameter $>16.5 \mu \mathrm{m}$ ) are densely innervated by VGLUT2 ${ }^{+}$axosomatic endings, and these neurons are the main source of the tectothalamic GABAergic projection to the MGB in all IC subdivisions (Fig. 7, cell 1). In contrast, the smaller GABAergic cells (Fig. 7, cell 2) lack this
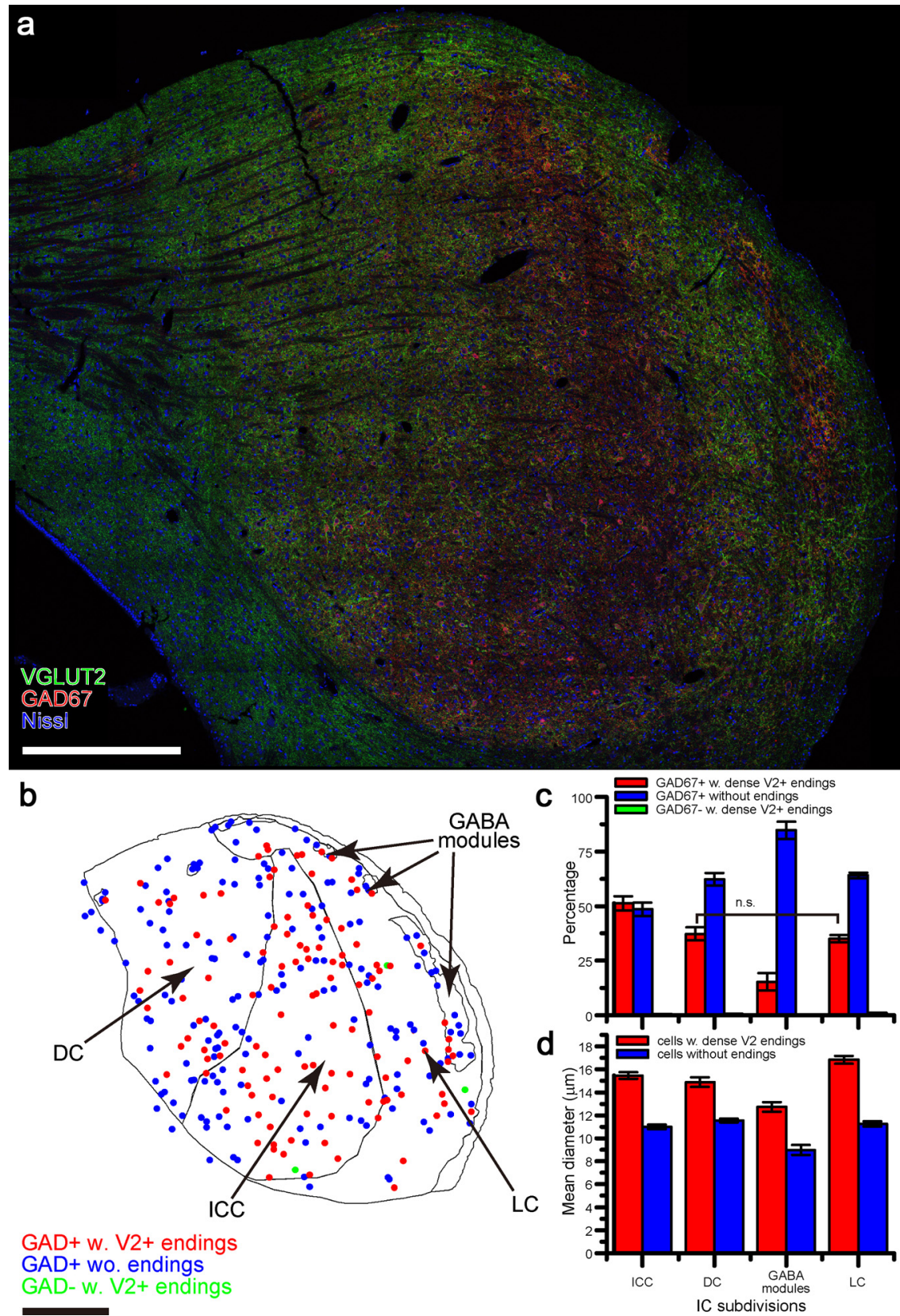

Figure 5. Distribution and size of $\mathrm{GAD} 67^{+} \mathrm{IC}$ neurons. $\boldsymbol{a}$, Composite image of whole IC section immunostained for VGLUT2 (green) and GAD67 (red) and counterstained with Neurotrace fluorescent Nissl dye (blue) reconstructed from 78 confocal images using a $\times 40$ lens (NA 1.3). GAD67 ${ }^{+}$cells with VGLUT2 ${ }^{+}$endings were distributed throughout the IC. The ICC and GABA modules (Chernock et al., 2004) are prominent at low magnification as red areas since there is less dense VGLUT2 immunoreactivity in these locations. $\boldsymbol{b}$, Drawing of the section in $\boldsymbol{a}$ showing the subdivisions of the IC and location of GAD67-immunopositive cells with and without VGLUT2 ${ }^{+}$axosomatic endings (red and blue dots, respectively). GAD67-negative cells with VGLUT2 ${ }^{+}$axosomatic endings were rare (green dots). c, Percentage of GAD67 ${ }^{+}$cells with VGLUT2 ${ }^{+}$axosomatic endings (red bars), GAD67 ${ }^{+}$cells without axosomatic endings (blue bars), and GAD67-negative cells with axosomatic endings (green bars) in subdivisions of the IC. $n=3$. $\boldsymbol{d}$, Mean diameters of GAD67 ${ }^{+}$somata with VGLUT2 ${ }^{+}$axosomatic endings (red bars), and without such endings (blue bars), in subdivisions of IC. $\ln \boldsymbol{b}-\boldsymbol{d}, n=3$; error bars in $\boldsymbol{b}$ and $\boldsymbol{c}$ indicate SEM. See also Tables S1 and S2. Scale bar, $500 \mu \mathrm{m}$.

specialized synapse and are the more common cell type in the cortical areas, especially in the GABA modules. The smaller GABAergic neurons must contribute to brain circuits other than the tectothalamic pathway. The tectothalamic circuit formed by large GABAergic neurons is different from excitatory tectothalamic projections provided by glutamatergic IC neurons (Fig. 7, cell 3), as those neurons also lack the specialized excitatory axosomatic inputs. 

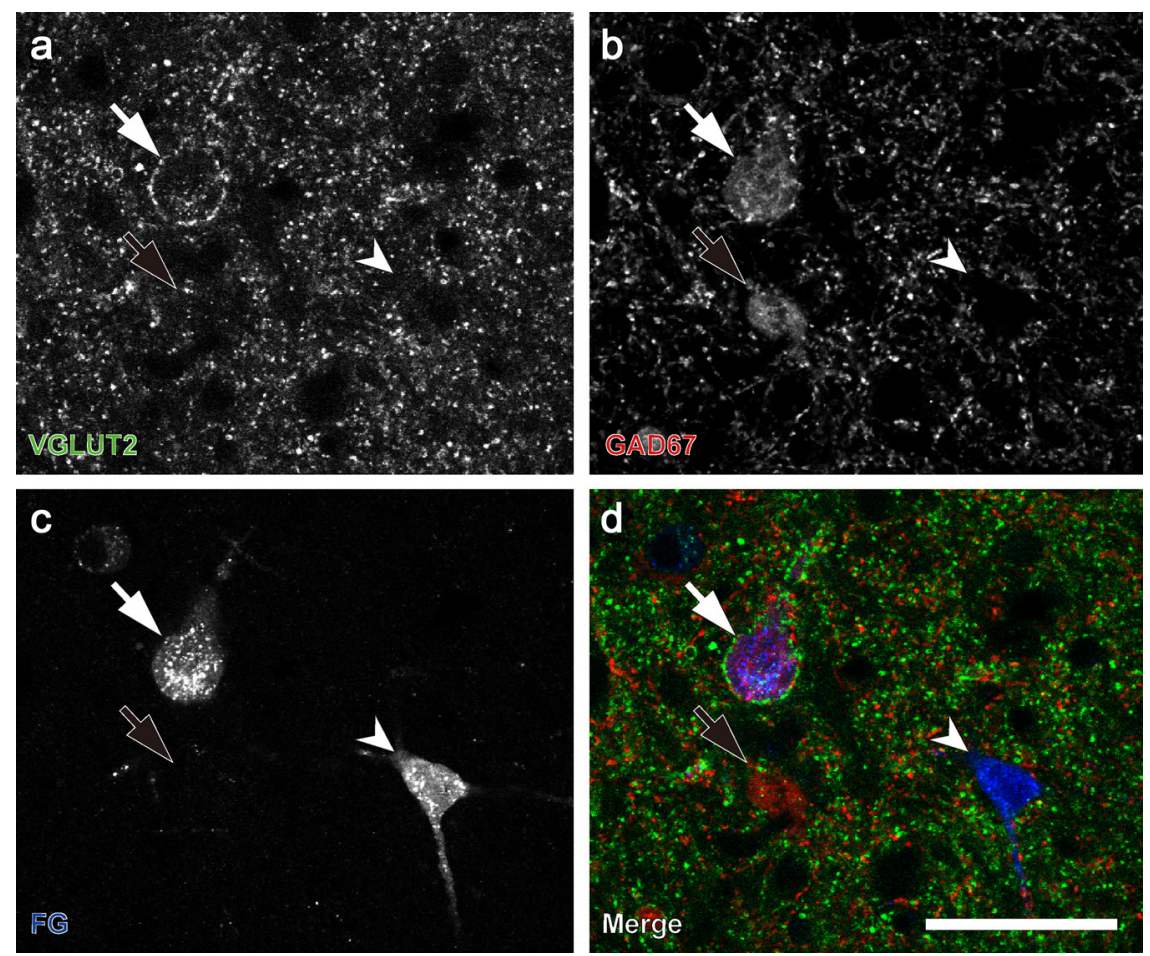

Figure 6. Identification of IC GAD67 neurons that project to the MGB. $\boldsymbol{a}$, One neuron with VGLUT2 ${ }^{+}$axosomatic endings (white arrow). $\boldsymbol{b}$, Large $\mathrm{GAD} 67^{+}$with axosomatic endings (white arrow) and a second GAD67 ${ }^{+}$neuron (black arrow) without axosomatic endings. $c$, After an FG injection into the medial geniculate body, retrogradely labeled FG-positive cells were found in the IC (white arrows and arrowheads). $\boldsymbol{d}$, The large $\mathrm{GAD} 67^{+}$cells with VGLUT2 ${ }^{+}$axosomatic endings were labeled with FG (white arrow). GAD67 ${ }^{+}$neurons without VGLUT2 ${ }^{+}$axosomatic endings were not labeled with FG (black arrows). The majority of FG-positive cells are negative for GAD67 (white arrowheads). Green, VGLUT2; red, GAD67; blue, FG. Scale bar: (in $\boldsymbol{d}$ ) $\boldsymbol{a}-\boldsymbol{d}, 50 \mu \mathrm{m}$.

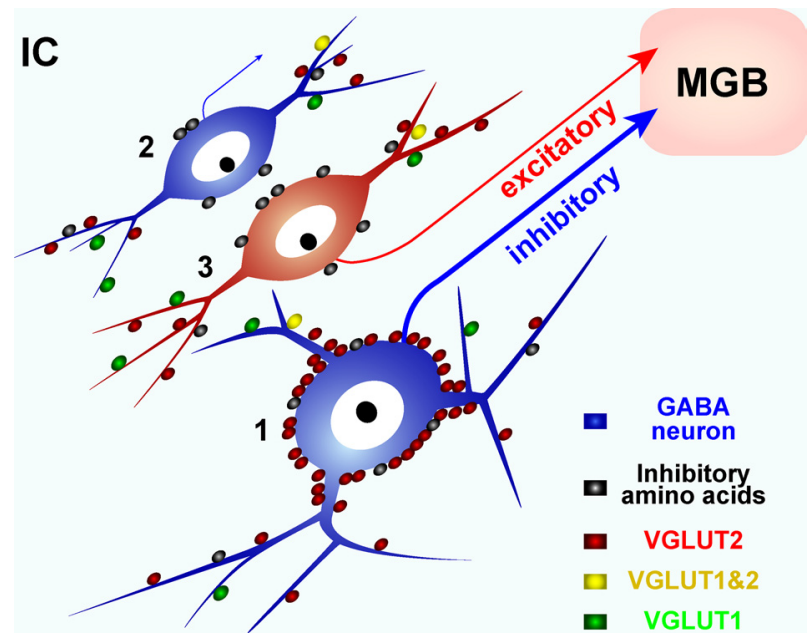

Figure 7. Threetypes of neurons in theIC. Large GABAergictectothalamiccells (1) are encircled by VGLUT2 ${ }^{+}$endings. Small GABAergic neurons lack axosomatic glutamate inputs (2). Non-GABAergic neurons (3) that presumably use glutamate as a transmitter express VGLUT2 (Herzog et al., 2001). There are two kinds of tectothalamiccells; inhibitory and excitatory, and the vastmajority of inhibitory tectothalamic neurons are large GABAergic cells with VGLUT2 ${ }^{+}$axosomatic endings. All cell types receive inhibitory axosomatic inputs (i.e., GABA and glycine) (Merchán et al., 2005). Note that distribution of terminals on dendrites is speculative.

\section{Technical considerations}

In the ICC, there was a clear separation into clusters of GAD67 ${ }^{+}$cells with or without dense VGLUT2 ${ }^{+}$terminals. However, in the DC, LC, or whole IC separate clusters were not as obvious (Fig. 4b,c; Fig. S1 $a$, available at www.jneurosci.org as supplemental mate- rial). One explanation is that fewer GABAergic neurons with VGLUT2 ${ }^{+}$axosomatic terminals are present in the DC and LC (Fig. 5c), making clusters less obvious in the scatter plots (Fig. $4 b, c$; Fig. S1 $a$, available at www.jneurosci.org as supplemental material). GAD $67^{+}$neurons were still fit by two bivariate Gaussian distributions in the whole IC and DC (Fig. S1b,c, available at www.jneurosci.org as supplemental material). These fits also show that the variance of the terminal density on smaller GAD67 ${ }^{+}$cells was higher in the whole IC and DC with more potential overlap between the two groups. Nevertheless, the two types of GABAergic cells were still separable on the basis of size.

A second complication was an overall higher density of VGLUT2 ${ }^{+}$terminals in the DC and LC (Fig. 5a). At the light microscopic level, it is impossible to discriminate between terminals with axosomatic synaptic contacts and terminals separated from cell bodies by thin glial processes. This may lead to misidentification of a proportion of the nonaxosomatic terminals as axosomatic endings in the DC and $\mathrm{LC}$, and increase the variability in the terminal density measurement (Fig. S1c, available at www.jneurosci.org as supplemental material). Our error rate for misclassification in the whole IC sample was $14.7 \%$, while in the sample of the ICC alone our error rate was only $8.7 \%$. So, accurate classification of the two types of GABAergic neurons is easiest in the ICC. Although the error rate is already low, the accuracy of classification may increase with analysis at the electron microscopic level or with additional markers to identify postsynaptic membrane proteins.

\section{IC cells with the dense axosomatic synapse}

The results from the few available EM studies are consistent with those reported here. Oliver (1984b) reported larger MGBprojecting IC cells had numerous axosomatic synapses in cats, and these were identified by stacked rough endoplasmic reticulum and highly infolded nuclei. That electron microscopic study concluded that large disc-shaped and stellate neurons were the recipient of the dense axosomatic endings. In an electron microscopic study of the IC of rats, Ribak and Roberts (1986) reported that larger neurons received dense axosomatic endings, while small neurons received only a few symmetrical axosomatic synapses. They also reported that the plexus of axosomatic endings extended to the primary dendrites. Roberts and Ribak (1987) in a similar investigation of GABAergic neurons, suggested that there was more than one type of GABAergic neuron in the ICC. They found further that the larger neurons were more densely covered with terminals. Although there are minor discrepancies, these previous reports all support our current findings of multiple classes of GABAergic neurons in the IC with VGLUT2 ${ }^{+}$axosomatic terminals on the larger GABAergic neurons.

\section{Source of dense VGLUT2 ${ }^{+}$axosomatic endings}

At this point, we cannot positively identify the source of the glutamatergic axosomatic terminals. Excitatory inputs in the IC 
originate from the ventral and dorsal cochlear nuclei (VCN and DCN) (Oliver, 1984a, 1987; Oliver et al., 1999; Malmierca et al., 2005b), the medial and lateral superior olive (Oliver et al., 1995), intermediate nucleus of the lateral lemniscus (suggested by Saint Marie et al. (1997a) and Riquelme et al.(2001)), auditory cortex (Feliciano and Potashner, 1995), and the IC itself (Moore et al., 1998; Malmierca et al., 2003, 2005a).

We can exclude the auditory cortex and VCN as potential sources of VGLUT2 ${ }^{+}$(and VGLUT1-negative) axosomatic endings: pyramidal cells in layer 5 of the cerebral cortex express VGLUT1 (Fremeau et al., 2001; Fujiyama et al., 2001), and these are the source of neocortical inputs to the IC. The VCN is the primary source of glutamatergic terminals in the superior olive including the calyx of Held, and these axons contain both VGLUT1 and VGLUT2 (Billups, 2005; Blaesse et al., 2005). Expression of both VGLUT1 and VGLUT2 genes by VCN neurons is supported by both the Allen Brain Atlas database (Lein et al., 2007) (http://www.brain-map.org/) and our preliminary results of in situ hybridization for VGLUT1 and VGLUT2 (data not shown). Since axosomatic endings on GABAergic neurons in IC contain only VGLUT2, it is unlikely that they originate in the auditory cortex or VCN.

On the other hand, collateral axonal branches of IC glutamatergic neurons and the axons of fusiform cells in the DCN are likely sources of VGLUT2 axosomatic terminals. IC neurons express VGLUT2 but not VGLUT1 (Herzog et al., 2001), and they make collaterals in the IC (Oliver et al., 1991; Malmierca et al., 1995, 2009). DCN fusiform cells are a second possible source since they express VGLUT2 but not VGLUT1 (unpublished data), and DCN axonal terminals with round synaptic vesicles make axosomatic synapses on IC cells along with other unlabeled terminals at the electron microscopic level (Oliver, 1984a). Furthermore, tectothalamic IC neurons were observed at the light microscopic level to have DCN axons in contact with their somata and dendrites (Oliver et al., 1999). We cannot exclude olivary and lemniscal sources of VGLUT2 ${ }^{+}$terminals; however, some neurons in these nuclei express both VGLUT1 and VGLUT2 (unpublished data).

\section{Functional questions}

Our data clearly indicate that only large GABAergic IC cells receive dense glutamatergic axosomatic endings. This finding raises some interesting questions about the circuitry of the IC and the projections to the MGB.

What is the purpose of the axosomatic excitatory inputs? In a passive membrane model, the synapses on the proximal parts of the cell produce larger synaptic currents at the initial segment with a faster rise time and a shorter latency compared with synapses on the distal dendrites (Rall, 1967). This view suggests that, in the present case, the dense axosomatic inputs may be more influential than distal inputs and help the neuron fire more quickly. This is especially important for large neurons compared with smaller ones, since larger cells have more surface area with greater membrane capacitance to overcome before they fire. These large IC neurons are likely to be the pause-buildup and sustained regular neurons that have the slowest membrane time constants (Ono et al., 2005; Sivaramakrishnan and Oliver, 2006). Therefore, the axosomatic VGLUT2 ${ }^{+}$synapses may help the large GABAergic neurons to fire quickly, despite their large size and slow time constants.
What is the purpose of the large GABAergic cell body?

The positive correlation between size of the neuronal cell body, diameter of the axons, and the conduction velocities (Cullheim, 1978; Lee et al., 1986; Sasaki, 1994) suggest that the large GABAergic cells have large axons with relatively fast conduction velocities. Indeed, in the BIC, the GABAergic axons had the largest diameter (Saint Marie et al., 1997b). Electrical stimulation of the BIC in the brain slice showed that IPSPs arrive in the auditory thalamus before the EPSP (Peruzzi et al., 1997). Thus, tectothalamic GABAergic cells may be larger to accommodate large axons with a faster conduction velocity than the glutamatergic tectothalamic neurons.

What is the role of feedforward inhibition in the MGB?

Separate channels of auditory information from the auditory brainstem and IC may or may not converge in the MGB. For example, separate on and off pathways have been observed in the MGB of the guinea pig, where an inhibitory input from the IC could explain the off response (He, 2001). IC axons form two types of glutamatergic terminals and one type of GABAergic terminal in the MGB (Bartlett et al., 2000). These presumably emerge from at least three different IC neuron types. However, it is unclear to what extent the segregation of inputs from different IC neuron types contributes to the segregation of auditory information in the MGB. Whether the large GABAergic IC neuron forms a segregated tectothalamic brain circuit remains an open question. Even if tectothalamic excitation and inhibition are both found in the same channel, a fast IPSP from the large GABAergic tectothalamic neuron may be important in the regulation of sound-evoked activity in the auditory thalamus.

\section{References}

Altschuler RA, Tong L, Holt AG, Oliver DL (2008) Immunolocalization of vesicular glutamate transporters 1 and 2 in the rat inferior colliculus. Neuroscience 154:226-232.

Bartlett EL, Smith PH (1999) Anatomic, intrinsic, and synaptic properties of dorsal and ventral division neurons in rat medial geniculate body. J Neurophysiol 81:1999-2016.

Bartlett EL, Stark JM, Guillery RW, Smith PH (2000) Comparison of the fine structure of cortical and collicular terminals in the rat medial geniculate body. Neuroscience 100:811-828.

Billups B (2005) Colocalization of vesicular glutamate transporters in the rat superior olivary complex. Neurosci Lett 382:66-70.

Blaesse P, Ehrhardt S, Friauf E, Nothwang HG (2005) Developmental pattern of three vesicular glutamate transporters in the rat superior olivary complex. Cell Tissue Res 320:33-50.

Blanchart A, De Carlos JA, López-Mascaraque L (2006) Time frame of mitral cell development in the mice olfactory bulb. J Comp Neurol 496:529-543.

Caspary DM, Raza A, Lawhorn Armour BA, Pippin J, Arnerić SP (1990) Immunocytochemical and neurochemical evidence for age-related loss of GABA in the inferior colliculus: implications for neural presbycusis. J Neurosci 10:2363-2372.

Caspary DM, Milbrandt JC, Helfert RH (1995) Central auditory aging: GABA changes in the inferior colliculus. Exp Gerontol 30:349-360.

Chernock ML, Larue DT, Winer JA (2004) A periodic network of neurochemical modules in the inferior colliculus. Hear Res 188:12-20.

Cullheim S (1978) Relations between cell body size, axon diameter and axon conduction velocity of cat sciatic $\alpha$-motoneurons stained with horseradish peroxidase. Neurosci Lett 8:17-20.

Feliciano M, Potashner SJ (1995) Evidence for a glutamatergic pathway from the guinea pig auditory cortex to the inferior colliculus. J Neurochem 65:1348-1357.

Fremeau RT Jr, Troyer MD, Pahner I, Nygaard GO, Tran CH, Reimer RJ, Bellocchio EE, Fortin D, Storm-Mathisen J, Edwards RH (2001) The expression of vesicular glutamate transporters defines two classes of excitatory synapse. Neuron 31:247-260.

Fujiyama F, Furuta T, Kaneko T (2001) Immunocytochemical localization 
of candidates for vesicular glutamate transporters in the rat cerebral cortex. J Comp Neurol 435:379-387.

He J (2001) On and off pathways segregated at the auditory thalamus of the guinea pig. J Neurosci 21:8672-8679.

Herzog E, Bellenchi GC, Gras C, Bernard V, Ravassard P, Bedet C, Gasnier B, Giros B, El Mestikawy S (2001) The existence of a second vesicular glutamate transporter specifies subpopulations of glutamatergic neurons. J Neurosci 21:181RC.

Hioki H, Fujiyama F, Taki K, Tomioka R, Furuta T, Tamamaki N, Kaneko T (2003) Differential distribution of vesicular glutamate transporters in the rat cerebellar cortex. Neuroscience 117:1-6.

Hioki H, Fujiyama F, Nakamura K, Wu SX, Matsuda W, Kaneko T (2004) Chemically specific circuit composed of vesicular glutamate transporter 3 - and preprotachykinin B-producing interneurons in the rat neocortex. Cereb Cortex 14:1266-1275.

Ito T, Hioki H, Nakamura K, Tanaka Y, Nakade H, Kaneko T, Iino S, Nojyo Y (2007) Gamma-aminobutyric acid-containing sympathetic preganglionic neurons in rat thoracic spinal cord send their axons to the superior cervical ganglion. J Comp Neurol 502:113-125.

Kaneko T, Fujiyama F, Hioki H (2002) Immunohistochemical localization of candidates for vesicular glutamate transporters in the rat brain. J Comp Neurol 444:39-62.

Lee KH, Chung K, Chung JM, Coggeshall RE (1986) Correlation of cell body size, axon size, and signal conduction velocity for individually labelled dorsal root ganglion cells in the cat. J Comp Neurol 243:335-346.

Lein ES, Hawrylycz MJ, Ao N, Ayres M, Bensinger A, Bernard A, Boe AF, Boguski MS, Brockway KS, Byrnes EJ, Chen L, Chen L, Chen TM, Chin MC, Chong J, Crook BE, Czaplinska A, Dang CN, Datta S, Dee NR, et al. (2007) Genome-wide atlas of gene expression in the adult mouse brain. Nature 445:168-176.

Llewellyn-Smith IJ, Minson JB (1992) Complete penetration of antibodies into vibratome sections after glutaraldehyde fixation and ethanol treatment: light and electron microscopy for neuropeptides. J Histochem Cytochem 40:1741-1749.

Loftus WC, Malmierca MS, Bishop DC, Oliver DL (2008) The cytoarchitecture of the inferior colliculus revisited: a common organization of the lateral cortex in rat and cat. Neuroscience 154:196-205.

Malmierca MS, Rees A, Le Beau FE, Bjaalie JG (1995) Laminar organization of frequency-defined local axons within and between the inferior colliculi of the guinea pig. J Comp Neurol 357:124-144.

Malmierca MS, Hernández O, Falconi A, Lopez-Poveda EA, Merchán M, Rees A (2003) The commissure of the inferior colliculus shapes frequency response areas in rat: an in vivo study using reversible blockade with microinjection of kynurenic acid. Exp Brain Res 153:522-529.

Malmierca MS, Hernández O, Rees A (2005a) Intercollicular commissural projections modulate neuronal responses in the inferior colliculus. Eur J Neurosci 21:2701-2710.

Malmierca MS, Saint Marie RL, Merchan MA, Oliver DL (2005b) Laminar inputs from dorsal cochlear nucleus and ventral cochlear nucleus to the central nucleus of the inferior colliculus: two patterns of convergence. Neuroscience 136:883-894.

Malmierca MS, Hernández O, Antunes FM, Rees A (2009) Divergent and point-to-point connections in the commissural pathway between the inferior colliculi. J Comp Neurol 514:226-239.

Merchán M, Aguilar LA, Lopez-Poveda EA, Malmierca MS (2005) The inferior colliculus of the rat: quantitative immunocytochemical study of GABA and glycine. Neuroscience 136:907-925.

Moore DR, Kotak VC, Sanes DH (1998) Commissural and lemniscal synaptic input to the gerbil inferior colliculus. J Neurophysiol 80:2229-2236.

Nakamura K, Watakabe A, Hioki H, Fujiyama F, Tanaka Y, Yamamori T, Kaneko T (2007) Transiently increased colocalization of vesicular glutamate transporters 1 and 2 at single axon terminals during postnatal development of mouse neocortex: a quantitative analysis with correlation coefficient. Eur J Neurosci 26:3054-3067.

Oliver DL (1984a) Dorsal cochlear nucleus projections to the inferior col- liculus in the cat: a light and electron microscopic study. J Comp Neurol 224:155-172.

Oliver DL (1984b) Neuron types in the central nucleus of the inferior colliculus that project to the medial geniculate body. Neuroscience 11:409-424.

Oliver DL (1987) Projections to the inferior colliculus from the anteroventral cochlear nucleus in the cat: possible substrates for binaural interaction. J Comp Neurol 264:24-46.

Oliver DL (2005) Neuronal organization in the inferior colliculus, Chap 2. In: The inferior colliculus (Winer JA, Schreiner CE, eds), pp 69-114. New York: Springer.

Oliver DL, Kuwada S, Yin TC, Haberly LB, Henkel CK (1991) Dendritic and axonal morphology of HRP-injected neurons in the inferior colliculus of the cat. J Comp Neurol 303:75-100.

Oliver DL, Winer JA, Beckius GE, Saint Marie RL (1994) Morphology of GABAergic neurons in the inferior colliculus of the cat. J Comp Neurol 340:27-42.

Oliver DL, Beckius GE, Shneiderman A (1995) Axonal projections from the lateral and medial superior olive to the inferior colliculus of the cat: a study using electron microscopic autoradiography. J Comp Neurol 360:17-32.

Oliver DL, Ostapoff EM, Beckius GE (1999) Direct innervation of identified tectothalamic neurons in the inferior colliculus by axons from the cochlear nucleus. Neuroscience 93:643-658.

Ono M, Yanagawa Y, Koyano K (2005) GABAergic neurons in inferior colliculus of the GAD67-GFP knock-in mouse: electrophysiological and morphological properties. Neurosci Res 51:475-492.

Parzen E (1962) On estimation of a probability density function and mode. Ann Math Stat 33:1065-1076.

Peruzzi D, Bartlett E, Smith PH, Oliver DL (1997) A monosynaptic GABAergic input from the inferior colliculus to the medial geniculate body in rat. J Neurosci 17:3766-3777.

Rall W (1967) Distinguishing theoretical synaptic potentials computed for different soma-dendritic distributions of synaptic input. J Neurophysiol 30:1138-1168.

Ribak CE, Roberts RC (1986) The ultrastructure of the central nucleus of the inferior colliculus of the Sprague-Dawley rat. J Neurocytol 15:421-438.

Riquelme R, Saldaña E, Osen KK, Ottersen OP, Merchán MA (2001) Colocalization of GABA and glycine in the ventral nucleus of the lateral lemniscus in rat: an in situ hybridization and semiquantitative immunocytochemical study. J Comp Neurol 432:409-424.

Roberts RC, Ribak CE (1987) An electron microscopic study of GABAergic neurons and terminals in the central nucleus of the inferior colliculus of the rat. J Neurocytol 16:333-345.

Saint Marie RL, Shneiderman A, Stanforth DA (1997a) Patterns of gammaaminobutyric acid and glycine immunoreactivities reflect structural and functional differences of the cat lateral lemniscal nuclei. J Comp Neurol 389:264-276.

Saint Marie RL, Stanforth DA, Jubelier EM (1997b) Substrate for rapid feedforward inhibition of the auditory forebrain. Brain Res 765:173-176.

Sasaki M (1994) Morphological analysis of external urethral and external anal sphincter motoneurones of cat. J Comp Neurol 349:269-287.

Silverman BW (1986) Density estimation for statistics and data analysis. London: Chapman and Hall.

Sivaramakrishnan S, Oliver DL (2006) Neuronal responses to lemniscal stimulation in laminar brain slices of the inferior colliculus. J Assoc Res Otolaryngol 7:1-14.

Varoqui H, Schäfer MK, Zhu H, Weihe E, Erickson JD (2002) Identification of the differentiation-associated $\mathrm{Na}^{+} / \mathrm{PI}$ transporter as a novel vesicular glutamate transporter expressed in a distinct set of glutamatergic synapses. J Neurosci 22:142-155.

Winer JA, Saint Marie RL, Larue DT, Oliver DL (1996) GABAergic feedforward projections from the inferior colliculus to the medial geniculate body. Proc Natl Acad Sci U S A 93:8005-8010. 